\title{
REPRESENTAÇÃO TEATRAL: ASSEMBLÉIA LEGISLATIVA DO ESTADO DO PARANÁ, INSTITUCIONALISMO E VETOS, de Luiz Demétrio Janz Laibida ${ }^{1}$
}

\author{
Rafael Egidio Leal e Silva ${ }^{2}$
}

- Enviado em 20/02/2016

- Aprovado em 24/02/2016

O trabalho aqui resenhado refere-se à Dissertação de Mestrado defendida no Programa de Pós-Graduação em Sociologia da Universidade Federal do Paraná, de autoria de Luiz Demétrio Janz Laibida, orientado pelo professor Doutor Ricardo Costa de Oliveira e co-orientada pelo professor Mestre Sérgio Soares Braga, defendida em 2007 na cidade de Curitiba. O objetivo da dissertação é analisar a existência de uma representação teatral do parlamentar no contexto da Assembleia Legislativa do Paraná, utilizando o institucionalismo, como a possibilidade de transformação da instituição, e a investigação a respeito dos vetos como instrumentos de comprovação das hipóteses do trabalho, e como forma de se alcançar o objetivo traçado.

O tema por si só é bastante interessante por se tratar de uma visão interessante e interdisciplinar sobre a política, especialmente a política regional paranaense. A primeira impressão que o leitor tem com o título e com a introdução do texto é a de se questionar os limites entre a arte e a política, além de remeter ao político como um ator, a Assembleia como como um palco e a

\footnotetext{
${ }^{1}$ Dissertação de autoria de Luiz Demetrio Janz Laibida, defendida no Programa de Pós-Graduação em Sociologia da UFPR, na linha Sociedade e Estado, em 2007, sob orientação do Prof. Dr. Ricardo Costa de Oliveira. Versão completa disponível na Biblioteca Digital da UFPR - http://www.pgsocio.ufpr.br/docs/defesa/dissertacoes/2007/luiz-demetrio.pdf

${ }^{2}$ Graduado em Ciências Sociais - Licenciatura (2008) pela Universidade Estadual de Maringá. É Mestre em Psicologia (2012) pela Universidade Estadual de Maringá. Atualmente é docente na área de conhecimento de Sociologia no Instituto Federal do Paraná - Campus Umuarama. Endereço eletrônico: rafael.silva@ifpr.edu.br .
} 
atuação política como um drama. A palavra drama, cuja origem etimológica vem do grego "ação" é perfeitamente cabível para neste sentido. De acordo com Aristóteles, em sua Poética, ao caracterizar a poesia imitativa de Homero e Sofócles, que imitavam "pessoas de caráter elevado" (1991, p. 203) e deste e Aristófanes que "imitam pessoas que agem e obram diretamente" (idem, p. 203). Conclui o estagirita que "tais composições se denominam dramas, pelo fato de se imitarem agentes" (idem, p. 203, grifo no original). Se assim considerarmos, partindo da premissa que nos leva a presente dissertação, é a política atual uma forma de ação de agentes, porém teatral, dramática, ou, ainda imitativa de agentes.

A visão de Aristóteles é ainda mais interessante quando entendemos o contexto de sua visão de ciência. Para ele, toda ciência ou é Teorética (a que busca a verdade, como a lógica, a matemática, a biologia, a física, etc.), ou é Prática (aquela que conduz a ação do homem, como a Ética e a Política) ou é Produtiva (que, como o nome diz, visa produzir coisas, como a metalurgia, a culinária ou a arte). Esta é também uma concepção hierárquica, na visão do filósofo macedônio. As ciências Teoréticas são superiores às Práticas, que por sua vez são superiores às Produtivas. Pensando aqui nas ciências que nos interessam, as Práticas (e a Política) e as Produtivas (e a Poética que produz a arte, que por sua vez produz sentimentos), percebemos que a Política era, para ele, uma Ciência Prática, ou seja, uma ciência que conduz a ação do homem em relação ao governo e interesses da cidade, ou da vida conjunta (uma vez que o homem é um animal político). A Poética obra que trata da produção da arte, era para ele uma Ciência Produtiva. Se a política é hoje uma forma de ação que pode ser muito mais caracterizada como uma atua-ação dramática teatral - um drama imitativo dos seus agentes, e não como uma forma de condução da vida comunitária humana, podemos perceber que há alguma coisa de podre no reino da Dinamarca, como diria um certo dramaturgo inglês que sabia muito bem transformar as ações políticas em arte genuína. Infelizmente, se hoje nossos políticos fazem o caminho inverso, é tempo de repensar a própria política.

Se a presente dissertação já pode despertar no leitor tantas reflexões, a forma que ela foi organizada é também idônea à sua proposta. O primeiro capítulo, intitulado "Etnografia da assembléia legislativa: paradigmas da representação teatral e da instituição legislativa paranaense", inicia com uma tentativa de etnografia da assembleia legislativa paranaense, tecendo como o dia a dia dos inúmeros personagens, políticos, burocratas, servidores, clientes, configura-se na grande pantomima a que o autor pretende demostrar. Infelizmente esta etnografia não foi estendida por mais algumas páginas, o seria muito interessante para o leitor, principalmente, uma vez que a 
narrativa do autor, ainda que breve, vislumbra como o conjunto de ações nos leva ao drama a que ele faz menção. Sociologicamente amparado por Pierre Bourdieu, o autor caracteriza a Assembleia como campo e a prática ali inserta, o habitus dos agentes. Na sequencia, o autor analisa a teoria do institucionalismo, e política a partir das instituições. E claro, embora as instituições possuam um alto grau de previsibilidade e formalismo, a discussão do autor demonstra que há possibilidades de mudanças nas instituições, principalmente através da abordagem neo-institucionalista, que é uma corrente mais abrangente que a antiga. Em seguida, o autor discute as concepções teóricas acerca do poder legislativo, enfocando o caso brasileiro, e expondo a fragilidade do parlamento (especialmente os estaduais) frente ao poder executivo, considerado como o centro do governo em nosso país, o ultrapresidencialismo. Discute também a concepção de Sérgio Abranches, o presidencialismo de coalizão no contexto legislativo brasileiro. Por fim, discute o contexto sociológico de representação do legislativo, mostrando que este poder, em sua configuração social, é um campo a ser explorado pelo pesquisador sociológico, e aprofunda aqui a questão da representação teatral dos deputados para a plateia (os eleitores). A discussão fecha o primeiro capítulo, desvelando as misteriosas relações que envolvem o jogo do poder.

O segundo capítulo, intitulado "Análises sobre o conceito de veto: contexto histórico e perspectivas sociológicas contemporâneas". Dividido em quatro partes, este capítulo mostra em sua primeira parte o histórico dos vetos, enfatizando as mudanças conceituais e aplicativas. $\mathrm{Na}$ segunda parte, o autor expõe algumas interações de veto, além de alguns conceitos (como veto parcial, total e player). Na terceira parte, é apresentada a relação existente entre o Executivo e o Legislativo nas pertinências do veto, mediada pela análise neo-institucionalista. Finalizando o capítulo, o autor apresenta as relações de veto no poder local, ilustrando com estudos já realizados em São Paulo. Sustentamos aqui que o autor escolheu muito bem o aspecto a ser investigado para corroborar seu objetivo de evidenciar o drama teatral na política local paranaense. Conforme podemos refletir, o capítulo primeiro mostra que o poder Legislativo é em geral fragilizado em relação ao Executivo, mas o político brasileiro, até mesmo por conta do personalismo que é característico de nossas relações de poder, deve sempre se apresentar como um forte, como alguém que faz a diferença em sua parcela de poder, no partido, na assembleia ou na sua região. Deve ele portanto, convencer seu eleitor que é ele o protagonista de sua peça teatral, o que lhe renderá aplausos efusivos (votos) ao final. Desta forma, o veto é uma interessante manifestação da relação entre tais poderes, e um interessante espaço de disputa legislativa e política. Afinal, esta é uma disputa que ocorre não apenas entre poderes, mas entre partidos, famílias, interesses regionais que podem inclusive ser invisíveis aos olhos da investigação científica. 
O terceiro capítulo, intitulado "Análise dos vetos no legislativo paranaense no período de 1996 à 2006" que corresponde à um total de 4.697 projetos de lei referente à este período. $\mathrm{O}$ autor apresenta sua discussão corroborada por uma série de tabelas e estatísticas, indo à fundo em sua investigação acerca do histórico de projetos e vetos no período referenciado. Nesta análise, podemos vislumbrar que na relação conflitiva que seria o veto, é na verdade um jogo já previsto dentro da instituição, ou ainda, uma peça já ensaiada e vendida para uma plateia que já espera tal comportamento de seus atores.

Citemos aqui uma parte de suas Considerações Finais:

Podemos concluir que a maior parte do tempo dos deputados estaduais do Paraná é dedicada à "representação", através de intermédios de alianças com o Poder Executivo do Estado, cuja presença é "visível" no "jogo" dos vetos, facilitadas nas abordagens neo-institucionalistas, entre elas a maior independência das instituições, como a Assembléia Legislativa do Estado do Paraná. (Laibida, 2007, p. 72)

As Considerações Finais, portanto, coloca fim neste trabalho tendo seus objetivos alcançados e plenamente justificados, não apenas academicamente, mas para todo aquele interessado no jogo da política e no comportamento do político brasileiro local. Podemos vislumbrar como as práticas do personalismo, clientelismo e patrimonialismo estão presentes no jogo cotidiano da política. Como todo teatro, o autor apresentou a parte do espetáculo, mas deixou claro que existem os bastidores, os ensaios, que é onde a mágica acontece, mas que é lugar proibido para aqueles que não são considerados aptos a estar ali (evidentemente, a presença de um investigador científico não seria bem aceito ali). O texto possui um apêndice, que trata das funções do legislativo, o processo legislativo, a elaboração da lei, a estrutura do legislativo paranaense, seu funcionamento, estrutura e instalações, os órgãos da assembleia, Direção liderança e bancadas, representação do legislativo nos municípios. O texto possui também quatro anexos.

Desta forma, o presente texto, além de ser uma análise científica exemplar, é um trabalho instigador, tanto para o pesquisador da política ou da sociologia como para o público em geral. De linguagem acessível, o texto poderia facilmente ser transformado em livro, o que seria uma grande contribuição às publicações de Ciência Política no Brasil. O texto pode ser utilizado tanto em fins acadêmicos como para fins didáticos, devido sua facilidade de leitura e clareza da exposição. 


\section{Referências bibliográficas.}

ARISTOTELES. Poética. 4.ed. São Paulo: Nova Cultural, 1991. Col. Os pensadores.

LAIBIDA, L. Representação teatral: assembléia legislativa do estado do paraná, institucionalismo e vetos. 2007. 112f. Dissertação (Mestrado em Sociologia)- Universidade Federal do Paraná, Curitiba/PR, 2007. 